\title{
Ferramentas Digitais na Conservação do Art Déco
}

\author{
Digital Tools in Art Deco Conservation
}

○ Fábio Ferreira de Lima

Programa de Pós-graduação Projeto e Cidade, Faculdade de Artes Visuais, Universidade Federal de Goiás, Goiânia, GO, Brasil.

fabio.lima@ufg.br

\section{Resumo}

Os edifícios históricos podem nos comunicar uma grande quantidade de informações e fundam numa determinada comunidade um sentido de origem, assim como qualidades singulares de identidade. Para uma cidade que estava sendo construída, o patrimônio art déco de Goiânia surgiu principalmente como caráter simbólico de poder e progresso. Hoje, bastante disperso no meio de tantas outras edificações, requer considerações sensíveis. Esse tipo de arte edificada não é simples resultado da composição funcional de volumes, nem muito menos mera decoração de superfície, mas a representação de visões e valores de época. Constituem inegáveis bens culturais que devem ser investigados para fins de melhores usos urbanos, como referências fundamentais na compreensão do passado. Dentro das nossas atuais circunstâncias, as tecnologias digitais são ferramentas que podem contribuir decisivamente na conservação desse patrimônio.

Palavras-chave: Conservação. Art Déco. Arte edificada. Ferramentas Digitais.

\begin{abstract}
Historical buildings can communicate many quantities of information to us and to establish a sense of origin in a given community as well as unique qualities of identity. For a city that was being built, Goiânia's art decó heritage emerged mainly as a symbolic character of power and progress. Today, widely dispersed among so many other buildings, it requires sensible considerations. This type of built art is not simply the result of the functional composition of volumes, much less mere surface decoration, but the representation of visions and period values. They are undeniable cultural assets that must be investigated for the purpose of better urban uses, as fundamental references in the understanding of the past. Within our current circumstances, digital technologies are tools that can contribute decisively to the conservation of this patrimony.
\end{abstract}

Keywords:Conservation. Art Deco. Edified art. Digital Tools. 


\section{Introdução}

Os edifícios históricos são frequentemente referenciais nas experiências dos moradores da cidade. Constituem alusões de suas vidas, como objetos que ancoram uma memória. Não são notáveis apenas por caracterizar uma determinada expressão construtiva ou artística, mas porque permitem constatar o passado daquela população, assinalando certas condições específicas do lugar e distinguindo valores de época. A visão do patrimônio é assim, aquela que corresponde ao modo como uma comunidade assume seu tempo passado, em bases sob as quais erigiram sua identidade (CHOAY, 2001). Um passado que não pode ser por completo apreendido, mas que deixou nos objetos as marcas desse tempo. A memória, as percepções individuais não podem ser guardadas intactas por muito tempo, e tendem a se perder junto com outras impressões. Elas apenas subsistem por meio de outros objetos. O edifício, através de sua materialidade, nos permite o resgaste de uma parte desse passado.

2

Os edifícios art déco de Goiânia, por exemplo, reafirmam essa trajetória antiga, um testemunho material através de um conjunto de condições adversas que acabaram por culminar nas suas características. Ao mesmo tempo em que pode revelar uma visão de época, o edifício histórico permite abrir um conjunto específico de coisas a serem pensadas. Nas percepções gerais do lugar, por exemplo, os fundamentos dos raciocínios espaciais, as tecnologias empregadas, a vertente expressiva, etc., além de um passado que não se pode mais restituir e torna-se alvo de uma escavação profunda, na busca por seus vestígios. E sempre há uma grande dificuldade de adaptar as funções criadas no passado com atividades atuais, no sentido de manter sua vitalidade. Assim, outros aspectos incertos surgem para garantir a preservação, ao readequar essas atividades: como se dá a alocação de novos usos frente ao presente tão variável e complexo?

Os edifícios inscrevem assim numerosas dúvidas, e elas servem para assinalar problemas: procura-se lançar mão de estratégias e novas perspectivas para valorizar 
e conservar esse patrimônio. Desse modo, quais ferramentas nos estão disponíveis atualmente para que essas tarefas possam ser melhor desempenhadas? Como vivemos um período de revolução das tecnologias, como elas podem ampliar o campo das estratégias de conservação nas suas mais diversas qualidades? Como instrumentos de grande valia do nosso tempo é preciso pensar também em como podem ser úteis à recomposição dos edifícios nesse tempo vigente, pois se prestam ao escrutínio de suas características.

Esses questionamentos podem ser subsidiados por autores que discutem esse assunto, como Françoise Choay (2001), Celina Manso (2004), Wolney Unes (2001), Gustavo Coelho (2004). Como são indissociáveis do campo social, os conceitos de Maurice Halbwachs (2006) e James Clifford (1916) estabelecem referências valiosas também. Já os fundamentos dos usos das ferramentas digitais são discutidos a partir de Manuel Castells (1999), Arlindo Machado (2000) e outros, criando interlocuções entre esses autores.

Os objetos arquitetônicos de valor histórico, como os edifícios art déco de Goiânia, são fundamentais porque podem ser considerados objetos únicos, frágeis como uma peça de arte digna de investigação, repletos de significados a serem reconhecidos. E aí talvez um dos maiores desafios seja porque não são conservados num museu, mas nos "circuitos da vida" (CHOAY, 2001). No contexto urbano, ainda que distanciados pelos valores com que foram edificados num determinado tempo, não deveriam se tornar estéreis, pois estão sempre permeados por diferentes dinâmicas da vida em geral.

Assim, muitas das referências possibilitadas pelos edifícios parecem nostálgicas, um tempo decorrido que as pessoas insistem capturar como fragmento, como memória coletiva (HALBWACHS, 2006), ou constituição de uma identidade não tão fácil de ser reconhecida. Trazer esse passado à tona às vezes pode ser como olhar uma fotografia antiga e nela não se reconhecer. Uma imagem desgastada pelo 
tempo que foi implacável nas suas investidas e corroeu sua aparência. Ver aquela imagem antiga é buscar um resquício, uma parte de nós que ainda é possível de se transportar, pelo esforço de ainda sermos capazes de nos enxergarmos nela.

\section{Entre Arte e Cultura}

Talvez um dos maiores problemas no contexto cultural esteja mesmo na relação do tratamento dos objetos, no modo como se dão os critérios para as escolhas do quê preservar, incidindo muitas vezes em certos sistemas subjetivos de valores. Dependendo do olhar do historiador, os objetos culturais podem assumir diversas outras funções, cumprindo atribuições de memória, patrimônio, arte edificada. Assim, se entendermos a cultura de um modo genérico como uma interposição antrópica, a arte é uma das suas mais privilegiadas expressões e frequentemente sofre pesadas críticas porque seus valores são muito flutuantes no decorrer do tempo.

A arte edificada nesse caso é ainda mais complexa, porque efetiva aquele ideário de congregar num único corpo todas as outras expressões visuais: não as sobrevaloriza, mas são tratadas igualmente como manifestações importantes. Essa complexidade se dá também porque, como já afirmou Bruno Zevi, a arquitetura é apreendida a partir da sua condição tridimensional e que inclui em si própria o homem. O edifício histórico pode ser considerado a partir das suas singularidades, da sua realidade exterior. Entretanto, sua compreensão ampla está para além do próprio corpo, por outras faces que não são imediatamente vistas, permanecem ocultas, mas que podem ser intuídas. Assim, há de se considerar que nesses edifícios os valores semânticos (sentidos objetivos e figurados pretendidos) bem como pragmáticos (apropriados num dado contexto cultural), precisam de esforço interpretativo, não são dados diretamente. Dentro dessa perspectiva, há um processo de reinterpretação daquela realidade, ancorada por documentos e outras fontes materiais.

Em função de vivermos um sistema capitalista capaz de corromper todas as esferas de produção, do patrimônio edificado aos mínimos objetos (mobiliário, 
utensílios, pertences pessoais de época, etc.), tudo parece ser capaz de adquirir novos status. Nesse sentido, os pesquisadores lançam mão de técnicas, conceitos e formas de abordagens específicas para a avaliação de suas qualidades.

Uma das figuras centrais no processo de desconstrução da etnografia clássica, o antropólogo e historiador James Clifford (1916), parte do princípio que "identidade, seja cultural ou pessoal, pressupõe atos de coleção, recolhendo pertences em sistemas arbitrários de valor e significado. Tais sistemas, sempre poderosos e regidos por regra mudam historicamente" (CLIFFORD, 1916, p.96) ${ }^{1}$. Sua crítica deriva do fato de que a civilização ocidental criou, de modo muito perverso, o caráter de posse (necessidade de domínio, apreensão dos objetos para catálogo, hierarquização, taxonomias) na intenção de satisfazer o ego, além da exibição pública com fins de souvenir.

Essa fala revela um trânsito muitas vezes escamoteado sob o discurso cultural e que necessita ser averiguada com atenção. Para o autor, a distinção do sentido auferido entre arte e cultura é dada pelos peritos (que devem ser criticados, observados também), capazes de apontar certas singularidades em tudo aquilo que é de significância cultural. E o alerta dado pelo autor, não apenas no sentido de compreender profundamente os valores que esses objetos trazem, mas também no fato de haver interessados compostos por museus de arte, especialistas, eruditos e mercados publicitários com fins não apenas culturais, mas principalmente turísticos, de exploração comercial. Isso pressupõe assim que a preservação de um autêntico domínio da identidade não pode ser natural ou inocente:

Todas essas coleções incorporam hierarquias de valor, exclusões, territórios regidos por regras pessoais. Mas a noção de que esse encontro envolve a acumulação de bens, a ideia de que a identidade é uma espécie de riqueza (de objetos, conhecimento, memórias, experiência), certamente não é universal (CLIFFORD, 1916, p.96) $)^{2}$

$1 \quad$ "...identity, whether cultural or personal, presupposes acts of collection, gathering up possessions in arbitrary systems of value and meaning. Such systems, always powerful and rule governed, change historically" (CLIFFORD, 1916, p.96).

2 "All such collections embody hierarchies of value, exclusions, rule-governed territories of the self. But the notion that this gathering involves the accumulation of possessions, the idea that identity is a kind of wealth (of objects, knowledge, memories, experience), is surely not universal" (CLIFFORD, 1916, p.96). 
$\mathrm{Na}$ visão do autor, não é universal porque o tratamento do patrimônio cultural possui abordagens diferentes em outros lugares, no que tange a sua reverência. No ocidente, a coleta dos exemplos é uma estratégia para suprir uma necessidade de avaliação, de submeter o objeto ao escrutínio máximo, fragmentando-o nas suas unidades de sentido. Nesse desejo de domínio, aprende-se a selecionar, ordenar, classificar em hierarquias para fins demonstrativos. Assim, a acumulação desdobrase de forma pedagógica e edificante (CLIFFORD, 1916). Nessas escolhas muitos espécimes parecem não ter vez, por não apresentarem ressonância na sociedade atual. Não causam impacto, boa parte das vezes são singelos. Esses costumam ser desprezados. Ao que tudo indica, para serem efetivamente notados precisam do discurso da autoridade, o porta-voz capaz de tirá-los do estado invisível em que se encontram. Aos olhos de uma boa parte da população, a cidade contém um número muito extenso de objetos sem valor, são assim percebidos como obsoletos, arcaicos (quando não ao extremo inúteis). Não se inserem como integrantes fundamentais das narrativas do passado.

Para o autor, a distinção entre arte e cultura é em boa parte dada por um campo de poder aberto pela palavra. Proporcionaria assim favorecimentos, quando aponta a singularidade num conjunto extenso de manifestações culturais, e devem estar permanentemente sob atenção, já que estão sob o crivo de especialistas.

Nesse trânsito haveriam duas categorias principais de objetos catalogados: artefatos culturais e obras artísticas. A mudança de status entre estes ocorre frequentemente, onde uma expressão de arte pode ser vista como manifestação cultural (e nesse caso decresce de valor, já que esse coletivo é inferior e tende a se constituir como artesanato) ou ainda uma peça manufaturada poder ser recolhida como arte (ver Figura 01). A essa produção juntam-se mercadorias confeccionadas em série, cujo valor é sempre suspeito: um souvenir turístico, um objeto excêntrico ou exótico e que, desse modo, pode ser da ordem do inautêntico. 


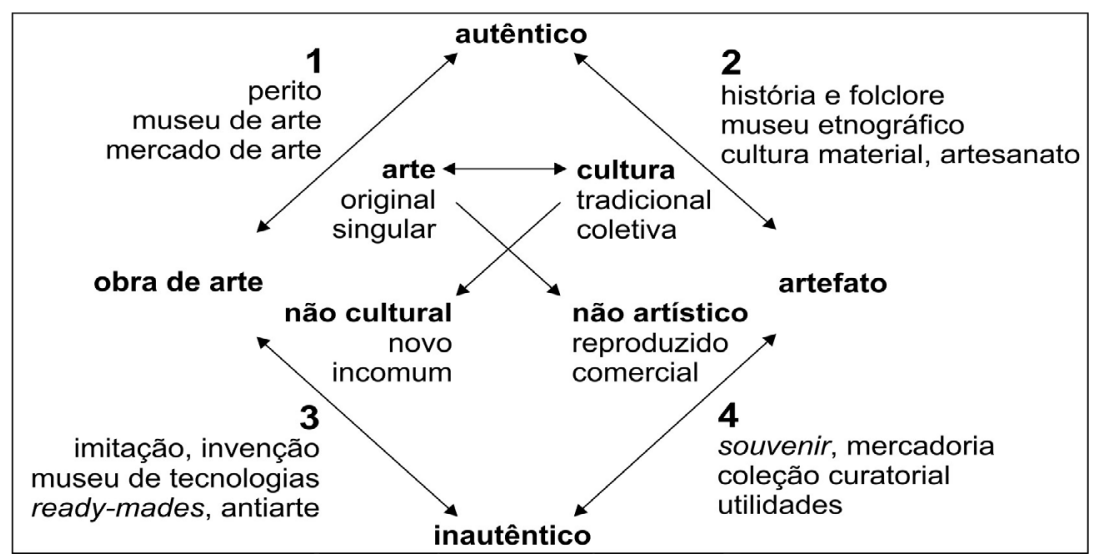

Figura 1- O sistema arte-cultura: o processo de se fazer autenticidade. Diagrama de trânsitos entre objetos disputados pelo valor de patrimônio (ou de exploração como mercadoria). Fonte: Clifford (1916).

Esse sistema de produção arte-cultura se desenvolve num processo de oposição entre quatro zonas semânticas cujos sentidos mais próximos podem estar derivados do autêntico, inautêntico, da obra de arte e do artesanato. Assim tem-se a zona das obras autênticas (1), dos artefatos autênticos (2), das obras primas inautênticas (3) e dos artefatos inautênticos (4) (CLIFFORD, 1916). Esses núcleos ocorrem com certa frequência, demonstrando que toda a parte superior é dessa ordem do verdadeiro, genuíno ou legítimo. A noção de autêntico é também, em outras palavras, a de mais valia, aquilo que adquire força simbólica adequada nas condições de um suposto estatuto social, dos valores patrimoniais capazes de serem reconhecidos por ela. Essa discussão tomou repercussões entre autores bastante respeitados, como Jacques Le Goff, Stuart Hall, Françoise Choay, pois com a expansão dos negócios no tempo presente, as fronteiras tornaram-se cada vez menos diferenciáveis e "os produtos técnicos da indústria adquiriram os mesmos privilégios e direitos à conservação que as obras de arte arquitetônicas e as laboriosas realizações da produção artesanal” (CHOAY, 2001, p.209).

Essa é uma questão premente no art decó de Goiânia que por conta do seu aspecto singelo apresenta pouca força aos olhos da população. Muitos edifícios foram demolidos e vários outros (recentemente tombados) estão desprezados pelo poder público, sem qualquer uso, abandonados, causando ainda mais o distanciamento da população. Nesses edifícios, o espaço em si pode readequar funções, cujo verdadeiro 
caráter só pode constituir sentido a partir do seu uso. A arquitetura deve se apresentar útil, deve favorecer seus usuários, mesmo que suas funções sejam reprogramadas. $E$ assim o rol das funções básicas pode estar permanentemente em aberto, onde também diferentes usuários estabeleçam novas relações com aquele lugar.

\section{Goiânia e o Patrimônio Art Déco}

Muitos profissionais goianos lutam há anos por um maior reconhecimento do patrimônio cultural existente na capital, edifícios que foram elaborados segundo questões funcionais específicas e também desenvolvidas num período de um movimento de vanguarda: o art déco.

A tarefa artística num projeto de arquitetura requer uma reflexão muito profunda, pois ela não é mero resultado contingencial de superfícies ou muito menos paira gratuitamente sobre suas faces. As escolhas foram feitas de modo consciente para exprimir um tipo de verdade (conforme a realidade social e econômica), segundo

8 um ambiente cultural vivido nas suas inúmeras dificuldades e anseios, além das proposições estéticas que se queriam também assumir.

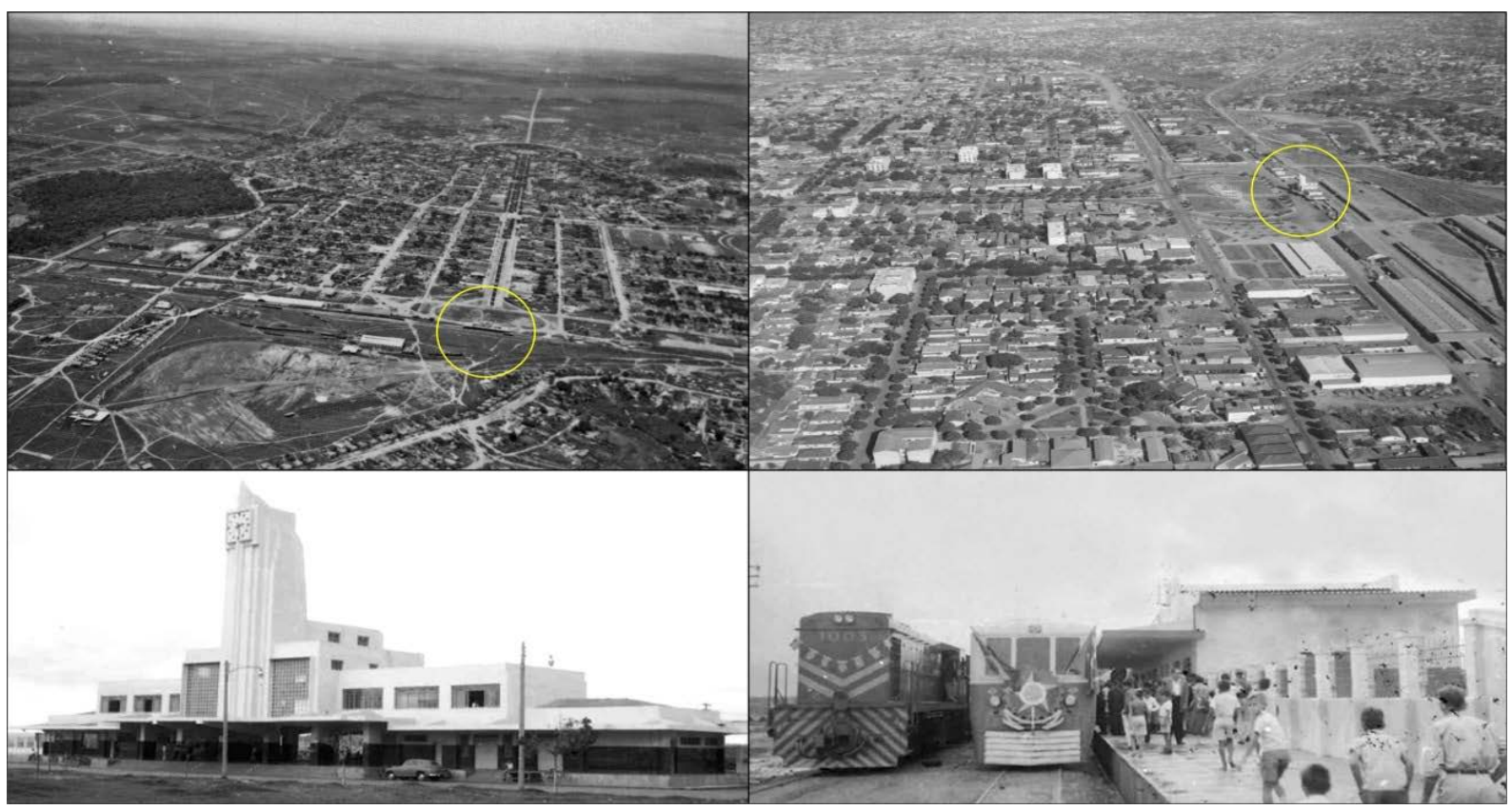

Figura 2- Goiânia e a implantação da Estação Ferroviária.

Fonte: Divisão do Patrimônio Histórico da Secretaria Municipal de Cultura de Goiânia. Fotos de Hélio de Oliveira entre as décadas de 1950 e 1960. 
Dentro dessa expectativa, para que a cidade tivesse um caráter simbólico de poder, era necessário dotá-la de edifícios favoráveis a esse tipo de percepção. Como desenvolver um arquétipo de um cenário de poder e progresso? Como congregar a um sistema construtivo uma capacidade de exprimir tal sentimento à população, valendo-se da dificuldade de dominar a matéria? Ou ainda, como a matéria podia ser o suporte mais imediato para essa tal enunciação? Para todas essas perguntas muitas respostas foram dadas e, as mais prementes delas encontrou no art déco a solução.

Surgido em Paris na Exposição Internacional das Artes Decorativas e Industriais Modernas de 1925 (UNES, 2001), o art déco consolidou-se como proposta em várias áreas do design, decoração, mobiliário, vestuário. Embora “...fosse criticado pelos seguidores do modernismo mais austero de Le Corbusier e da Bauhaus, compartilhavam o gosto pela máquina, pelas formas geométricas e pelos novos materiais e tecnologias" (DEMPSEY, 2003, p.135). Para facilitar a explanação, o quadro resumo abaixo apresenta as principais variações surgidas no estilo:

\begin{tabular}{ll}
\hline tipo & $\begin{array}{l}\text { descrição } \\
\text { - repetição ortogonal e simétrica de geometrias com } \\
\text { referencias às pirâmides maias, hindus, astecas ou ainda dos }\end{array}$ \\
zeométrico mesopotâmicos (DEMPSEY, 2003), (UNES, 2001); & $\begin{array}{l}\text { - abstração geométrica com forte influência da Bauhaus, do } \\
\text { cubismo, construtivismo e futurismo (HURLBURT, 2002); }\end{array}$ \\
- figuras repetidas ou sobrepostas, criando ritmo também por \\
pequenas variações de escala ou deslocamentos sucessivos.
\end{tabular}


Como o art déco se acentua na conformação de volumes puros, a maioria dos edifícios de Goiânia não era (e continua não sendo) muito reconhecido pelas pessoas. Um dos edifícios mais emblemáticos desse período, a Estação Ferroviária (ver Figura 02 e Figura 03), representava uma possibilidade de rápida transposição de fronteiras, pelo encurtamento de distâncias e a visualização de um ambiente geográfico simplificado, não somente em voga pelo uso das tecnologias das comunicações via rádio, como também pelos automóveis e trens (UNES, 2001).

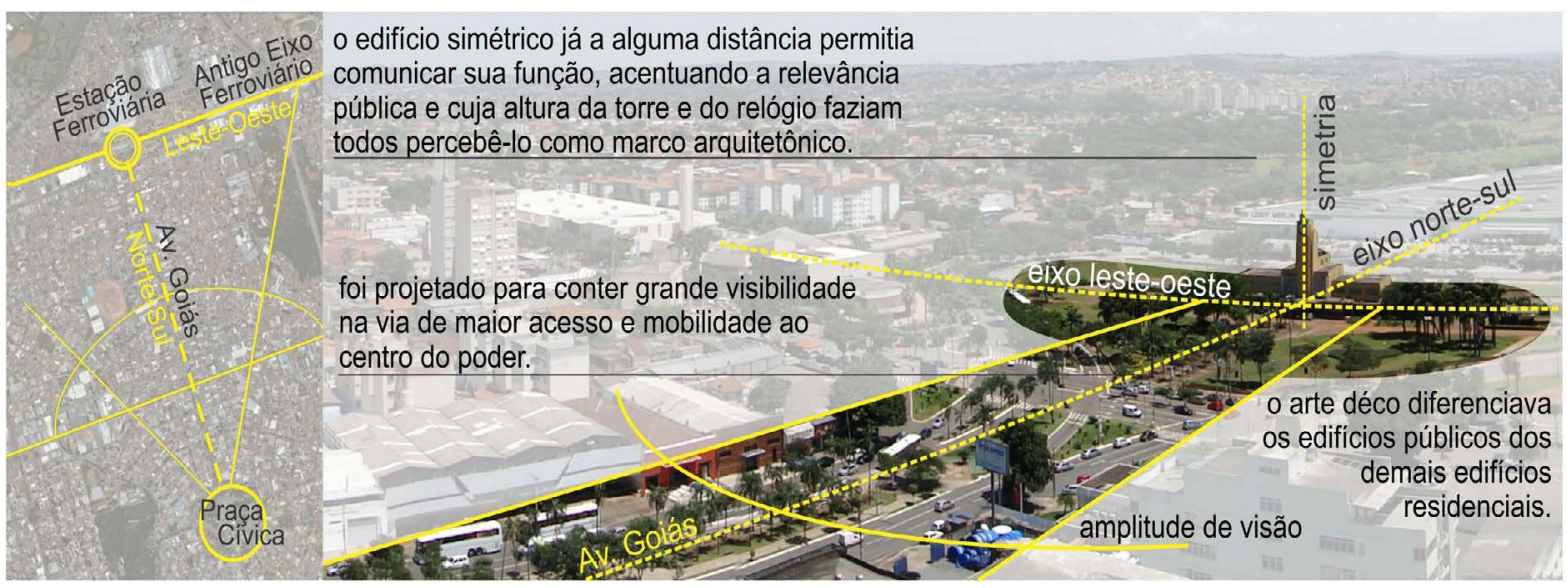

Figura 3 - Localização estratégica da Estação Ferroviária..

Fonte: Imagens modificadas a partir do banco de imagens do Google (2018).

Assim, impregnava-se o direito de ir e vir dos indivíduos, a individualidade e igualmente uma "lógica mercantilista sobre as idéias e as artes" (UNES, 2001, p.26). A estação ferroviária de Goiânia foi inaugurada em 11 de novembro de 1952, sendo que o Estado já possuía entre 1912 e 1952 quarenta e seis estações no interior do Estado (COELHO, 2004). No entanto, por inúmeros problemas políticos e financeiros, a ferrovia não deu continuidade para outros estados (na época o governo de Juscelino Kubitschek incentivava principalmente a construção de rodovias), e foi posteriormente desativada em 1980.

Os edifícios art déco de Goiânia foram tombados pelo IPHAN em 2003 e, embora boa parte deles tenham sido destruídos, cerca de outros 22 ainda são existentes (MANSO, 2004). Embora caracterizem claramente uma arte edificada, esses monumentos históricos, a exemplo de outras antiguidades são "também a descoberta da arte como atividade autônoma" (CHOAY, 2001, p.205) em vários 
sentidos, mas principalmente descoberta e aprendizado, e constituída como objeto a ser resignificado, nas conformidades às visões de mundo do homem que se alteram no tempo:

\begin{abstract}
Os edifícios do passado contribuíram para o estudo sistemático das formas plásticas, de seu desenvolvimento e classificação. As pesquisas dos antiquários acompanharam as dos naturalistas e participaram, com elas, da criação de uma civilização da imagem: instrumento de análise do mundo e suporte da memória (CHOAY, 2001, p. 206).
\end{abstract}

Por meio da arte edifícios são mediadores de outras intensidades que as formas podem ocasionar. E ainda que caracterizem expressões relativamente simples, integram um determinado conjunto de valor formador da identidade (CLIFFORD, 1916). Além disso, a experiência proporcionada é assumida como nova possibilidade da dimensão tectônica da arquitetura, de explorar a expressão possibilitada pelos materiais utilizados em conformidade aos seus principais atributos.

\title{
11 \\ Recursos Digitais na Conservação do Patrimônio Edificado
}

Dentro das nossas atuais condições de vida, é cada vez mais difícil pensar a produção arquitetônica sem o suporte das tecnologias digitais, sejam elas fotografias, vídeos, maquetes virtuais, ambientes virtuais imersivos, etc. De modo geral, os recursos tecnológicos vêm sendo utilizados ostensivamente no planejamento, criação, desenvolvimento, reforma e restauro da arquitetura e eles têm direcionado à uma mudança e uma melhoria do pensamento projetual. Assim se estabelecem como diálogo fecundo de instrumentos típicos do nosso tempo, acomodados a contingências específicas, capazes de revelar outros tipos de raciocínios adequados aos caracteres dos edifícios. O uso das tecnologias digitais permite aprofundar o conhecimento acerca das suas qualidades.

Esses instrumentos tornam-se fundamentais para ampliar os campos de investigação, bem como na construção de novos processos a serem examinados. A técnica faz parte do universo cultural. Na consecução dos fatos culturais, as 
técnicas encerram aspectos essenciais e "a arquitetura, por exemplo, sempre operou na intersecção perfeita da arte com a técnica" (MACHADO, 2000, p.11). Os objetos da cultura, materiais ou imateriais, devem ser pensados a partir dos procedimentos técnicos com que foram concebidos, bem como de características singulares que lhes são restritivas (CASTELLS, 1999).

Numa sociedade onde os indivíduos são cada vez mais anônimos, com pouca ou nenhuma distinção, generalizados como se não houvesse identidade, o patrimônio pode legitimar a construção social dos significados históricos. A identidade é construída a partir do reconhecimento dos valores, dos bens, da cultura local, do que se quer preservar. Assim, envolve autoconstrução, individuação (CASTELLS, 1999).

Os instrumentos digitais podem apresentar novas modalidades de 'ver', compreender, raciocinar o patrimônio edificado. Por exemplo, as fotografias digitais são capazes de extrair conteúdos que normalmente não parecem tão intensos como na realidade, onde são apropriadas para gerar um escrutínio das coisas (ver Figura 4). Evocam uma percepção ativa e crítica para o estado das coisas e, como se para além do próprio real, imputam uma realidade execrada. As minúcias não passarão desapercebidas, o olhar pode percorrer todas as extremidades atentamente. A fotografia permite uma análise por sinédoque, onde os fragmentos representam a visão intensa reveladora do todo. Por isso apresenta-se tão importante, um olhar que não se perde mais, não é fugaz, não é reminiscência.

Também os vídeos, ainda que restringidos por um quadro como as fotografias, estabelecem relações dinâmicas na apreensão do espaço que registra. Aqui, talvez, a noção espacial pode ocorrer com maior similitude à noção do próprio corpo como referência a percorrer as extensões tridimensionais. A noção de escala parece se apresentar de forma mais evidente. (ver Figura 5). 


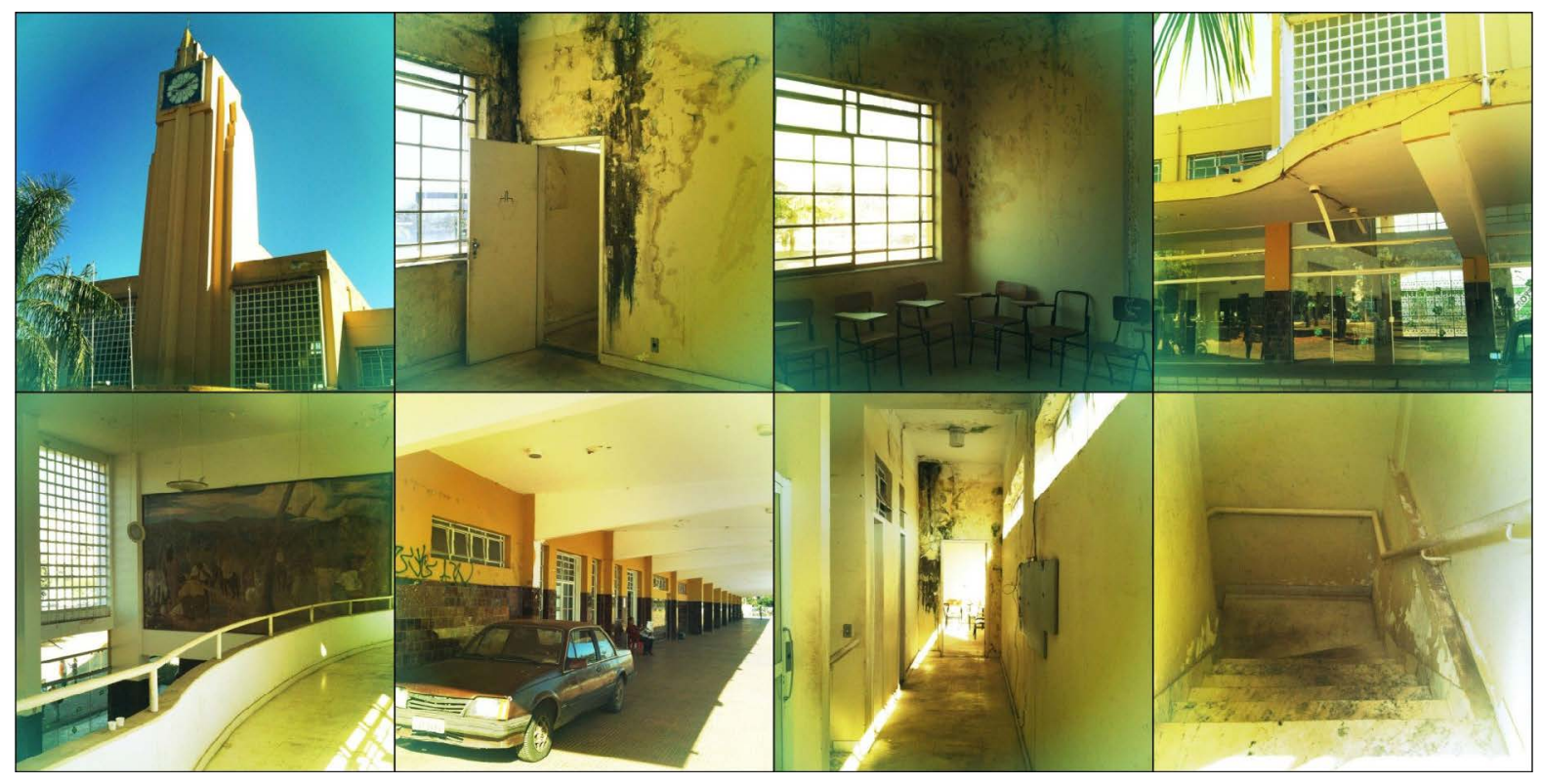

Figura 4 - Fotografias do atual estado de conservação da Estação Ferroviária. Fonte: Elaborado pelo autor (set 2018).

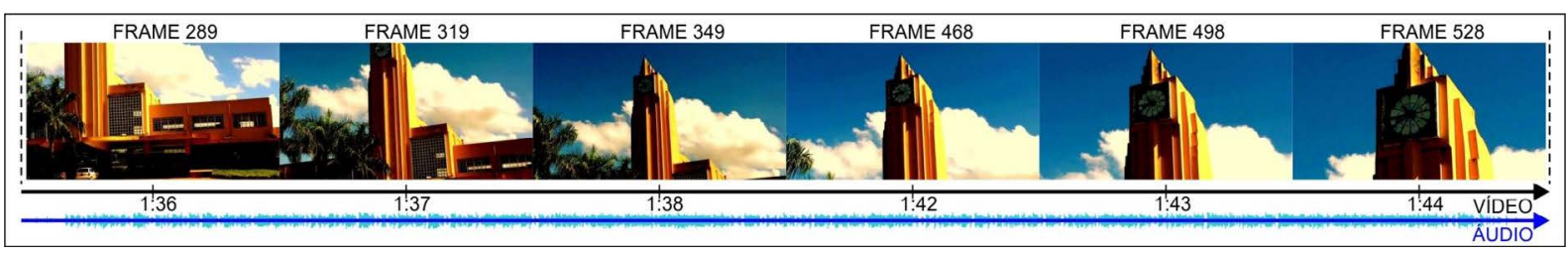

Figura 5 - Trecho de vídeo do atual estado de conservação da Estação Ferroviária. Fonte: Elaborado pelo autor (set 2018).

Já em relação às maquetes digitais, se mostram eficientes por possibilitar raciocínios espaciais mais complexos, além de simulações tridimensionais para tomadas de decisão mais acertadas. Os computadores acrescentam interessantes valores às representações espaciais, para além das qualidades de uma perspectiva, porque enquanto pontos de vista móveis, ofertam raciocínios amplos da apreensão espacial (ver Figura 6). As maquetes se apresentam fundamentais pelos distintos modos com que são representadas no computador (seus modos de visualização). A visão computacional oferta compreensão dos planos geométricos de modo mais contundente. Os raciocínios, as tomadas de decisão posteriores se darão mais conscientes.

Há um número muito vasto de técnicas e tecnologias que podem ser utilizadas para uma descrição sistematizada dos edifícios históricos e as suas escolhas dependem 
tanto das características da edificação (dificuldades de representação, dimensões e características, e principalmente quando se encontram muito deteriorados).

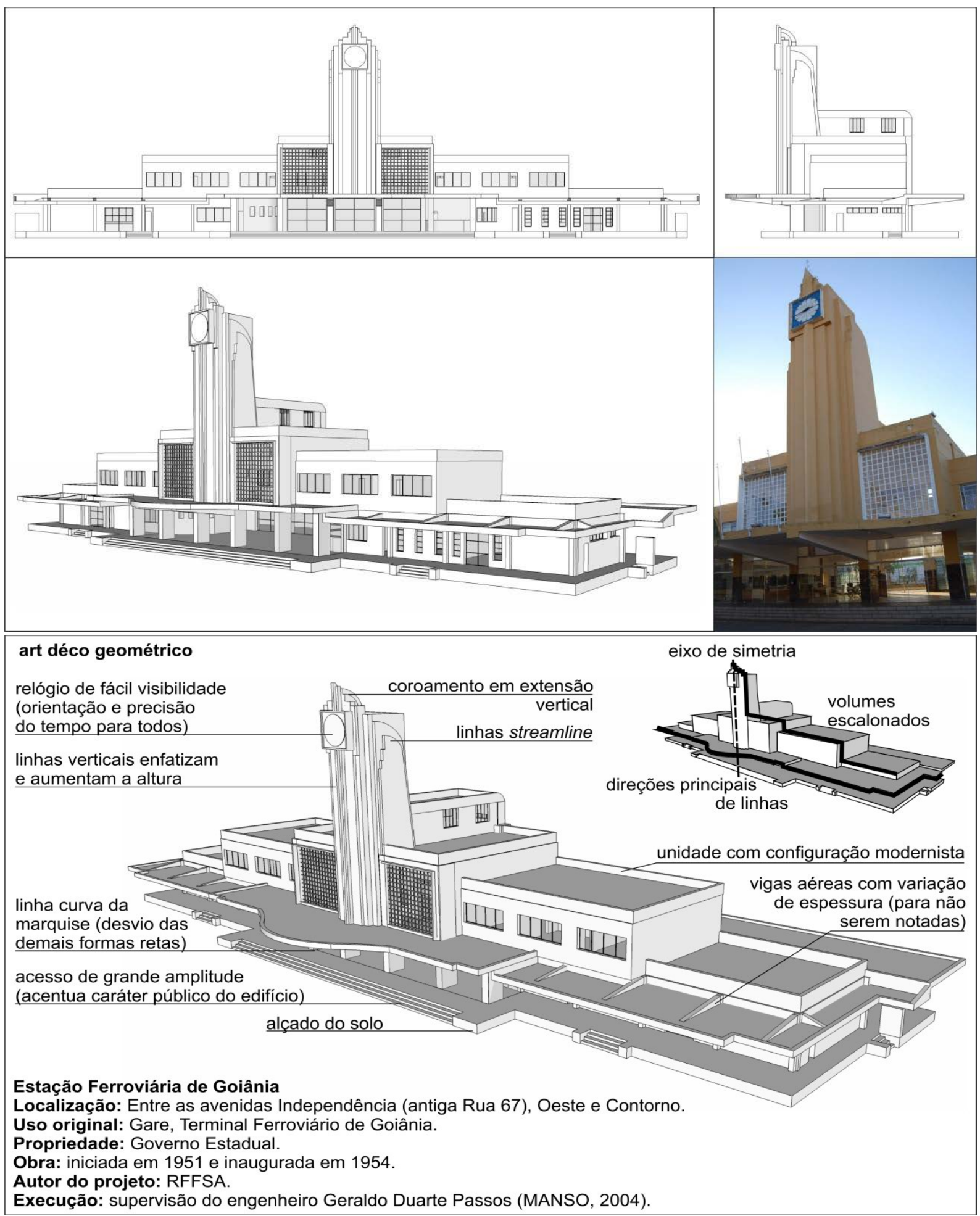

Figura 6 - Maquete e fotografia digital da Estação Ferroviária de Goiânia.

Fonte: Elaborado pelo autor. 
Além dessas mencionadas, as técnicas comumente empregadas são:

- Medição direta: tradicionalmente realizada com o auxílio de instrumentos simples, como trenas, fios de prumo e níveis. O levantamento é feito gradualmente por meio de esboços e anotações no papel. Os erros podem ser minimizados ao se utilizar instrumentos eletrônicos, tais como trenas e níveis a laser, goniômetros, aumentando a precisão e reduzindo o tempo de trabalho em campo (TOLENTINO; BRITO, 2014).

- Modelagem geométrica: conforme dito anteriormente, a confecção de um modelo digital permite visualização em vários ângulos e tem-se uma compreensão melhor do edifício. Os modelos podem ser feitos em vários softwares tais como SketchUp, 3ds Max, Rhinoceros, etc., ou ainda a partir da Fotogrametria Digital.

- Fotogrametria: técnica digital que permite elaborar a geometria por meio de duas ou mais fotografias tiradas em diferentes posições. Os pixels são identificados a partir das imagens e produzem suas coordenadas espaciais em softwares específicos como o PhotoModeler, PhotoScan, Recap 360, 123D Catch, etc. Assim é produzido um modelo que permite representações em vistas, plantas, cortes, perspectivas. Além disso, o mapeamento também feito por drones para uma melhor compreensão do sítio, a partir de mosaicos de ortofotos geram a forma da superfície ou do terreno, uma imagem georreferenciada a partir de softwares como Agisoft Photoscan, Pix4d Mapper Pro, Trimble Uas Master, etc.

Além dessas anteriormente citadas, muitas outras tecnologias têm surgido na arquitetura e urbanismo, com fins não apenas no cadastro de bens históricos, mas sim em domínios mais específicos, explanadas em inúmeras bibliografias. As principais são:

- Sistema de Informações Geográficas (SIG): sistema que envolve programas computacionais, conjunto de materiais de coleta e pessoas, 
na intenção de recolher, armazenar, recuperar, editar, visualizar e explorar informações espacialmente referenciadas. Por meio de sobreposição de mapas são obtidas informações comparadas, apresentando dados distintos, observando-se exatamente os pontos e as áreas de suas ocorrências. Bastante útil para a documentação cadastral, onde administradores ou gestores de projeto podem tomar decisões.

- Cadastro Territorial Multifinalitário (CTM): sistema de dados baseado numa parcela, contendo documentos legais de direitos e incumbências, além de benefícios sobre a terra (OLIANI, 2016), bem como um conjunto de dados gráficos e descritivos da região, a partir de informações georreferenciadas. Podem ser estabelecidos propósitos fiscais (avaliações, contribuições, taxas), na intenção de um desenvolvimento sustentável e a proteção do meio ambiente. Bastante relevante nas decisões da administração pública.

- Volunteered Geographic Information (VGI): ferramentas para criar, reunir e divulgar dados geográficos fornecidos voluntariamente por indivíduos. É um conteúdo criado por usuários, muitas vezes entendido por abordagens críticas e participativas sobre os sistemas de informações geográficas. Exemplos são o WikiMapia, OpenStreetMap e Yandex. Os usuários podem selecionar trechos que tenham levantado e alimentar a base de dados, assim como quaisquer outras fontes complementares.

- Laser Scanning: constitui-se de uma tecnologia de medição e digitalização de alta precisão, aumentando significativamente o detalhe e a redução de erros. O objeto é iluminado a laser e realiza-se uma varredura do edifício, processado então em um software, produzindo um modelo geométrico formado por pontos. Essa nuvem de pontos constitui a modelagem geométrica, com alto grau de precisão e realismo.

- Building Information Modeling (BIM): conjunto de dados gerados e mantidos por todos os períodos de vida do edifício via uso de software, cuja base é o trabalho colaborativo, a partir de informações coordenadas e 
consistentes. Para além da visualização do modelo sob diferentes perspectivas dos profissionais envolvidos (nas suas respectivas atuações), podem ser modificadas informações em tempo real, sem haver necessidade de gerar documentações em papel (EASTMAN, 2014). O BIM se mostra muito adequado ao patrimônio arquitetônico porque permite sua representação digital, estudos de possibilidades de modificação e sua manutenção para futuras gerações (TOLENTINO; BRITO, 2014). Como se trata de um modelo paramétrico, vínculos e hierarquias são estabelecidos entre os componentes do edifício, não apenas capazes de quantificar materiais, mas gerar informações extremamente úteis para a gestão. Os softwares mais comuns que lidam com essa tecnologia são: ArchiCAD, Bentley Architecture, Revit Architecture, Vectorworks Architecture (ver Figura 7).

- Historic Building Information Modeling (HBIM): extensão do conceito BIM, utilizado para analisar o ciclo de vida de uma edificação, permite gerar documentos, análises e conservação dos edifícios históricos. O mapeamento inicial é feito com laser scanning ou fotogrametria e posteriormente os objetos são convertidos para modelos paramétricos. Assim são associados componentes construtivos, materiais, propriedades, integrando informações relacionadas ao edifício. Como no BIM, permite a interoperabilidade entre especialistas, combinando dados em tempo real sem que haja incompatibilidade de formatos.

- Fabricação digital: compreende a produção de objetos físicos a partir de modelos digitais. O modelo desenvolvido no computador pode ser observado fisicamente e isso facilita a observação detalhada das suas características, suas qualidades tectônicas, expressão construtiva, etc. A fabricação computadorizada pode ser feita por diversos recursos, tais como corte laser, fresadoras de desbaste tridimensional, impressoras laser, equipamentos de técnicas formativas tais como dobragem, prensa, moldagem a vácuo, térmica, etc. 
- Ambiente virtual imersivo: ambientes virtuais acessados por capacetes, óculos, data gloves, na interação com cenários que permitem um espaço interativo, lidando com o corpo e as percepções das relações espaciais de modo sinestésico.

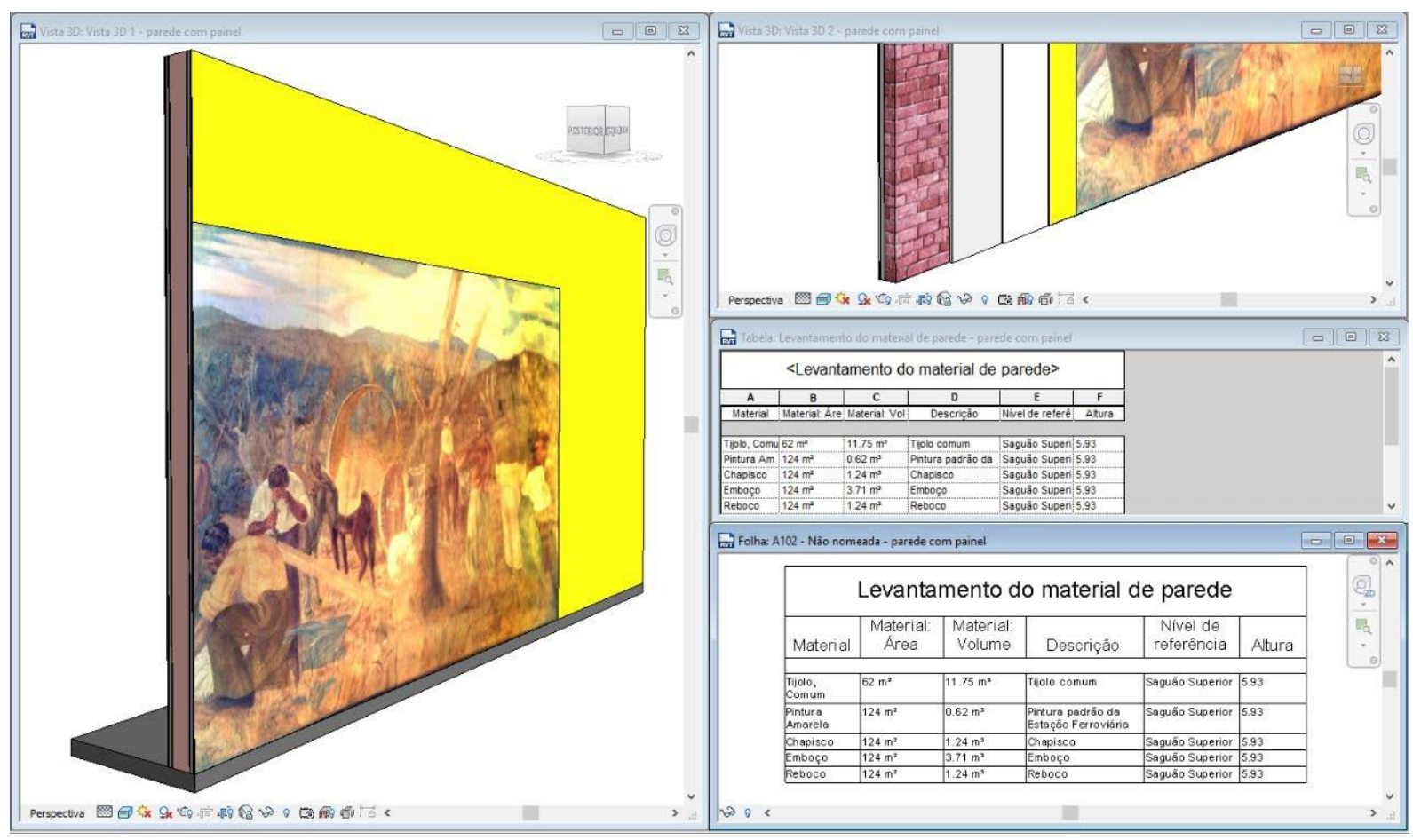

Figura 7 - Modelo BIM do painel produzido no saguão da Estação Ferroviária de Goiânia, a ser restaurado. $O$ artista plástico Frei Nazareno Confaloni realizou na década de 1953 dois painéis para a estação, retratando o cotidiano dos trabalhadores na construção da capital. Fonte: Elaborado pelo autor (set 2018).

Apesar das inúmeras facilidades proporcionadas pelas ferramentas digitais, muitas ainda são percebidas com desconfiança pelos arquitetos e pelos orgãos de preservação. De modo geral elas cumprem diferentes exigências de especialização requeridas pelas problemáticas projetuais: propiciam não apenas os enfoques desses problemas, mas também a avaliação, o diagnóstico, o controle de qualidade. Por outro lado, a importância dada não é centrar-se na tecnologia em si, mas no modo como seus benefícios são apropriados à conservação do patrimônio histórico, onde seus recursos são desejáveis e pertinentes. 
As novas tecnologias contribuem principalmente na manutenção do edifício, os patrimônios precisam frequentemente de manutenções preventivas e corretivas. Os modelos virtuais juntamente com os bancos de dados auxiliam no planejamento de uma manutenção, contendo os dados cadastrais e georeferenciais daquele edifício, auxiliando tecnicamente e economicamente, racionalizando o processo e minimizando falhas. A facilidade de "inserção" e "extração" de informação de um modelo paramétrico (BIM), por exemplo, (ver Figura 07) deve ser considerada na produção de projetos realizados pelos órgãos de preservação e manutenção desses patrimônios, principalmente pela diminuição de retrabalho, e pela capacidade de armazenamento dessas informações.

Projetos como o Programa de Aceleração do Crescimento - PAC Cidades Históricas do Governo Federal deveriam conter em suas linhas de atuação recursos para inclusão de tecnologias digitais no processo de elaboração das propostas de requalificação e revitalização de edifícios e áreas públicas. Isso facilitaria a coordenação do processo e propiciaria maior transparência em suas diferentes instâncias, tanto nos recursos destinados, quanto das licitações realizadas.

Assim, os edifícios podem ser reconstituídos, possíveis mudanças podem ser simuladas, suas organizações ou disposições podem ser testadas sob qualquer ângulo. Pois “...uma preocupação primordial na definição da identidade deve ser a manutenção, em certa medida, de seu passado arquitetônico e urbanístico" (MANSO, 2004, p.23). Os administradores da cidade contam com todos esses recursos e fazem seus estudos sobre os impactos de modo mais consciente. Podem realizar inspeções, discutir com a população, atuar em conjunto a equipes multidisciplinares.

Desse modo, o patrimônio cultural é identificado com o conjunto de valores atribuídos num sentido amplo, não especificamente nas manifestações e objetos em si, mas na dinâmica destes como sentido de vida (CHOAY, 2001). As ferramentas digitais permitirão, cada uma dentro de suas especificidades, aprofundamentos para investigar características e expressões individuadoras constituintes da identidade local, muitas vezes negligenciadas pelo poder público e pela população em geral. 


\section{Considerações Finais}

Nas últimas décadas a preservação do patrimônio cultural ganhou importância como assunto relevante no contexto das cidades, bem como nos projetos dos governos. Esses edifícios sempre representaram diferentes graus de interesse tanto pelo poder público quanto pela população.

De modo geral, as cidades só podem ser descritas quando falam dos seus espaços por meio dos monumentos, dos símbolos que nelas podem ser reconhecidos por uma grande parcela da população. São entidades específicas que desempenham no presente um valor de reverência e orgulho, assim como a reflexão pelo passado. Os edifícios históricos relacionam-se fundamentalmente com um sentimento de pertencer à cidade: fazer com que suas características sejam reconhecidas e preservadas.

Nesse contexto, os aparatos tecnológicos são cada vez mais especializados, cumprindo diferentes graus de exigência, interferindo substancialmente no modo como calculamos as coisas. Assim, as ferramentas digitais problematizam o que vemos e como vemos, pois são meios de compreensão dos fenômenos. Ao provocar novas percepções nos permitem reavaliar essa realidade. Como se pode notar, os meios de enunciação não são neutros. Ao contrário, se estabelecem como forças atuantes e intervenientes da percepção, prevalecendo uma ordem não-natural. Essas ferramentas requerem habilidades específicas para serem empregadas, influenciam diretamente nossas experiências e alteram profundamente nosso modo de pensar.

\section{Referências}

CASTELLS, Manuel. A sociedade em rede. A era da informação: economia, sociedade e cultura. São Paulo: Paz e Terra, 1999.

CHOAY, Françoise. A alegoria do patrimônio. Trad. Juliano Vieira Machado. São Paulo: Estação Liberdade: Ed. UNESP, 2001.

CLIFFORD, James. The Predicament of Culture: Twentieth Century Ethnography, Literature, and Art, Cambridge, MA: Harvard University Press, 1916. 
COELHO, Gustavo Neiva. Ferrovia: 150 anos de arquitetura e história. Goiânia: Trilhas Urbanas, 2004.

DEMPSEY, Amy. Estilos, escolas e movimentos. Trad. Carlos Eugênio Marcondes de Souza. São Paulo: Cosac \& Naify, 2003.

EASTMAN, Chuck. et al. Manual de BIM: um guia de modelagem da informação da construção para arquitetos, engenheiros, gerentes, construtores e incorporadores. Trad. Cervantes Golçalves Ayres Filho et al. Porto Alegre: Bookman, 2014.

HALBWACHS, Maurice. A memória coletiva. Trad. Beatriz Sidou. São Paulo: Centauro Editora, 2006.

HURLBURT, Allen. Layout: o design da página impressa. Trad. Edmilson O. Conceição, Flávio M. Martins. São Paulo: Nobel, 2002.

MACHADO, Arlindo. Máquina e Imaginário. São Paulo: Senac, 2000.

MANSO, Celina F.A. (Org.) Goiânia art déco: acervo arquitetônico e urbanístico dossiê de tombamento. Goiânia: Seplan, 2004.

OLIANI, Luiz O. Noções de cadastro territorial multifinalitário. Série de cadernos técnicos da agenda parlamentar. CREA, 2016. Disponível em <http://mundogeo.com/ arquivos/news/nocoes_cadastro_territorial-final.pdf> Acesso 16 set 2018.

UNES, Wolney. Identidade art déco de Goiânia. São Paulo, Ateliê Editorial; Goiânia, Ed. da UFG, 2001.

\section{NOTAS}

\section{Publisher}

Universidade Federal de Goiás. Faculdade/Instituto/Escola. Programa de Pós-graduação Projeto e Cidade. Publicação no Portal de Periódicos UFG. As ideias expressadas neste artigo são de responsabilidade de seus autores, não representando, necessariamente, a opinião dos editores ou da universidade.

RECEBIDO EM: 01/11/2021

APROVADO EM: 20/12/2021

PUBLICADO EM: 31/12/2021 